\title{
Evaluation study of cobalt(II) and strontium(II) sorption- desorption behavior for selection of soil remediation technology
}

\author{
I. Smičiklas ${ }^{1} \cdot$ S. Dimović ${ }^{1}$ M. Jović ${ }^{1}$ A. Milenkovié ${ }^{1} \cdot$ M. Šljivić-Ivanović ${ }^{1}$
}

Received: 1 September 2014/Revised: 26 February 2015/Accepted: 19 April 2015/Published online: 1 May 2015

(C) Islamic Azad University (IAU) 2015

\begin{abstract}
Sorption-desorption properties of cobalt(II) and strontium(II) ions were studied using a soil sample from the vicinity of the Serbian radioactive waste processing and interim storage facilities. The mobility of the cations in the soil was evaluated and compared with the intention to facilitate the selection of optimal remediation strategy in case of accidental soil contamination with radioactive cobalt-60 and strontium-90 isotopes. A systematic sorption study was performed through a series of batch experiments at different aging times, cation concentrations and $\mathrm{pH}$. Kinetics experiments revealed that sorbed amounts of cobalt(II) continuously increased with contact time until quasi-equilibrium was reached, while initial fast strontium(II) sorption was followed by a desorption step. Based on the shapes of the sorption isotherms and calculated sorption parameters, it was concluded that cobalt(II) sorbed more selectively and strongly than strontium(II). Sequential extraction showed that, regardless of the initial content of contaminants in the soil and the aging time, high amounts of both cations were bonded to relatively mobile fractions: strontium(II) in the exchangeable, while cobal$t(I I)$ in the carbonate and ferromanganese oxide fraction. Strontium(II) was readily desorbed in acidic, calcium(II) and ethylenediaminetetraacetic acid-containing media, whereas complexing agents such as citric and tartaric acids at low $\mathrm{pH}$ were more effective reagents for cobalt(II) desorption. The results from the present study indicate that chemical extraction can be considered as remediation option for strontium(II)- and cobalt(II)-contaminated soil.
\end{abstract}

S. Dimović

sdimovic@vinca.rs

1 Vinča Institute of Nuclear Sciences, University of Belgrade, P.O. Box 522, 11000 Belgrade, Serbia
Keywords Chemical extraction - Sequential extraction · Soil pollution $\cdot$ Radioactive ions $\cdot$ Remediation

\section{Introduction}

A number of human activities such as the commissioning of nuclear power plants, treatment and disposal of nuclear waste, nuclear weapons testing and use of radioactive isotopes in the industry and medicine carry a risk of environmental contamination with harmful radioactive pollutants. Naturally occurring radionuclides of uranium and thorium series along with the man-made isotopes [cobalt-60 $\left({ }^{60} \mathrm{Co}\right)$, cesium-137 $\left({ }^{137} \mathrm{Cs}\right)$, strontium-90 $\left({ }^{90} \mathrm{Sr}\right)$, plutonium-239 $\left({ }^{239} \mathrm{Pu}\right)$, americium-241 $\left({ }^{241} \mathrm{Am}\right)$, etc.] are the primary contaminants of concern (IAEA 1999). Once they enter the environment, radionuclides end up in soil and sediments, which are the major sinks for their accumulation. The long-term impact of certain radioactive contaminant onto ecosystems depends on its speciation, mobility and biological uptake (Salbu et al. 2004).

Problems of soil contamination with radioactive cobalt and strontium isotopes were addressed in several studies (Hsu et al. 1994; Park et al. 1994; USDOE 1996; Solecki 2005; Kamel 2010; Wallace et al. 2012; Dimović et al. 2013; Lavrentyeva 2014). ${ }^{90} \mathrm{Sr}$ is by-product of uranium and plutonium fission, and during the above-ground nuclear tests, accidents at nuclear power plants and leaks of liquid radioactive waste, it can be released into the environment (NCRP 1991). ${ }^{90} \mathrm{Sr}$ is $\beta$-emitter with half-life of 28.8 years. On the other hand, ${ }^{60} \mathrm{Co}$ is a $\gamma$-emitting activation product (half-life of 5.3 years) of stable ${ }^{59} \mathrm{Co}$, which is a common impurity in zircaloy and aluminum fuel cladding and in uranium metal fuel (Harmsen and Schulz 
1998). These radionuclides are common in liquid radioactive waste inventory, and often come together.

The investigation of divalent strontium $\left(\mathrm{Sr}^{2+}\right)$ sorption onto different soils showed that the metal distribution and selectivity of soils were strongly dependent on their chemical composition (Kamel 2010). In terms of chemical behavior, $\mathrm{Sr}^{2+}$ shows similarity to calcium, including high mobility. Using sequential extractions, it was determined that the majority of strontium was bonded to carbonate phase (Kamel 2010; Dimović et al. 2013). In contrast, divalent cobalt ions $\left(\mathrm{Co}^{2+}\right)$ are mainly associated with the fraction of ferromanganese (Fe,Mn) oxides and oxyhydroxides (Park et al. 1994; Dimović et al. 2013). From $\mathrm{Co}^{2+}$ sorption experiments onto different soil types, it was concluded that metal-ion binding was controlled by permanent charge, ion exchange sites of clay minerals or on amphoteric surface-hydroxyl edge sites of the same minerals and oxides, depending on solution conditions (USDOE 1996). Accordingly, the mobility of $\mathrm{Sr}^{2+}$ and $\mathrm{Co}^{2+}$ in the soil is fundamentally different.

Metal contamination in soil can be reduced by different management approaches (Singh and Prasad 2014). In order to conclude which remediation techniques (chemical extraction, electrokinetic processes, mechanical separation, soil additives, phytoremediation, etc.) are applicable in the case of soil contamination, sorption/desorption properties of specific radionuclide by the specific soil type must be clarified. Total concentration of the pollutant in the soil is a significant parameter; however, understanding the environmental behavior by determining its speciation is of principal importance for the selection of optimal remediation technologies (Mulligan et al. 2001).

Although it is generally acknowledged that testing metal distribution in the soil provides very useful information for evaluation of suitable remediation techniques and for monitoring their effectiveness, sequential extraction analysis is seldom performed in combination with leaching tests, especially for radioactive contaminants.

In this study, $\mathrm{Sr}^{2+}$ and $\mathrm{Co}^{2+}$ sorption/desorption properties were investigated using soil sampled in 2013, within the "Vinča" Institute of Nuclear Sciences (Belgrade, Serbia). This soil is particularly interesting as a model one, because the only radioactive waste management and storage facility in Serbia is situated at this location, and the accidental contamination with ${ }^{90} \mathrm{Sr}$ and ${ }^{60} \mathrm{Co}$ is possible. Sorption of cations was firstly investigated as a function of contact time, metal concentration and solution $\mathrm{pH}$. The distribution of metals between different soil fractions was analyzed and compared by sequential extraction method, while desorption efficiency was investigated using different leaching media. The results were analyzed with the implications to possible remediation strategies.

\section{Materials and methods}

\section{Characteristics of soil sample}

As a representative soil, a sample from the "Vinča" Institute was considered. Top sample (to the depth of $20 \mathrm{~cm}$ ) was taken from the area of $1 \times 1 \mathrm{~m}$. Once the larger stones, leaves, plant roots, etc., were removed, the soil was spread over filter paper sheets and left to dry for 15 days, in the air atmosphere and at room temperature. Dried soil was comminuted and homogenized in the mortar. It was sifted in order to obtain a fraction of particles $<2 \mathrm{~mm}$, for further experimental work.

In the previous study (Dimović et al. 2013), characterization of the sample has revealed that the soil was medium carbonated $\left(5.4 \% \mathrm{CaCO}_{3}\right)$, with a very low content of accessible phosphorous (7.4 mg per $100 \mathrm{~g} \mathrm{P}_{2} \mathrm{O}_{5}$ ) and medium content of potassium ( $12 \mathrm{mg}$ per $100 \mathrm{~g} \mathrm{~K}_{2} \mathrm{O}$ ). The quantity of total organic carbon was $2.1 \%$. Sample exhibited weak alkaline reaction with water (8.0) and low cation exchange capacity (13 meq per $100 \mathrm{~g}$ ). Furthermore, XRD analysis showed that the sample consisted mainly of quartz, kyanite and muscovite, with smaller quantities of mica, albite, kaolinite and calcium, magnesium carbonate (Dimović et al. 2013).

\section{Sorption experiments}

To explore and compare the influence of various process parameters onto sorption of ${ }^{90} \mathrm{Sr}$ and ${ }^{60} \mathrm{Co}$ by soil, experiments were conducted in batch conditions. Taking into account the same chemical reactivity of radioactive and stable isotopes of an element, stable isotopes were used in this study, as they are safer and more economical to work with. $\mathrm{Co}\left(\mathrm{NO}_{3}\right)_{2}$ and $\mathrm{Sr}\left(\mathrm{NO}_{3}\right)_{2}$ salts of analytical purity were dissolved in distilled water in order to obtain solutions of desired cation concentrations. Unless otherwise stated, the following conditions were constant in all sorption experiments:

- Experiments were conducted at room temperature $\left(21 \pm 1{ }^{\circ} \mathrm{C}\right)$, in air atmosphere;

- $1.000 \mathrm{~g}$ of soil was mixed with $20.00 \mathrm{~mL}$ of a cationcontaining solution, in 50-mL Falcon tubes;

- Suspensions were equilibrated using overhead laboratory shaker (Reax, Heidolph), at a constant speed of $10 \mathrm{rpm}$;

- For $\mathrm{pH}$ adjustments, variously concentrated $\mathrm{HNO}_{3}$ and $\mathrm{NaOH}$ solutions were used in minimum quantities;

- Liquid/solid phase separation was achieved by centrifugation at $7000 \mathrm{rpm}$ for $10 \mathrm{~min}$, and subsequent filtration through blue band filter paper (approximate pore size $2-3 \mu \mathrm{m}$ ); 
- InoLab WTW pH meter, equipped with glass SenTix ${ }^{\circledR} 81$ electrode with temperature compensation, was used for $\mathrm{pH}$ measurements and it was regularly calibrated using WTW buffer solutions;

- Depending on the range, concentrations of cations were measured either by Perkin Elmer 3100 Atomic Absorption Spectrometer (AAS) or by Thermo iCAP6500 Inductively Coupled Plasma-Optical Emission Spectrometer (ICP-OES). Perkin Elmer single element reference solutions were used for instruments calibration and measurements. Quality control samples, including blanks and duplicates were analyzed. Relative standard deviations of the means of duplicate measurement were commonly $\sim 3 \%$.

\section{Sorption kinetics}

In order to evaluate the sorption kinetics, separate batches were allowed to age for different time intervals, in the range from $30 \mathrm{~min}$ to 30 days. Initial concentration of both cations was $1.5 \times 10^{-3} \mathrm{~mol} \mathrm{~L}^{-1}$, whereas initial $\mathrm{pH}$ was adjusted to 5.7 .

\section{pH effect}

Influence of initial $\mathrm{pH}$ onto cation sorption was examined in the range 1.5-10 for $\mathrm{Sr}^{2+}$. A shorter range (1.5-8) was selected for $\mathrm{Co}^{2+}$ to avoid its hydrolysis and precipitation prior to the contact with the soil. Initial cation concentration was $1.5 \times 10^{-3} \mathrm{~mol} \mathrm{~L}^{-1}$. Based on the kinetic experiments, contact time was set at 4 days.

\section{Sorption isotherms}

For the construction of sorption isotherms and determination of maximum sorption capacities, initial cation concentrations were varied in the wide range from $10^{-4}$ to $10^{-2} \mathrm{~mol} \mathrm{~L}^{-1}$. Initial $\mathrm{pH}$ of all prepared solutions was adjusted to 5.7, whereas contact time was set at 4 days. A blank experiment, with distill water instead of $\mathrm{Co}^{2+}$ and $\mathrm{Sr}^{2+}$ solutions, was performed under the same experimental conditions. The quantities of released $\mathrm{Ca}^{2+}$ ions were determined after $\mathrm{Co}^{2+}$ and $\mathrm{Sr}^{2+}$ sorption, and in the blank.

\section{Sequential extraction}

$\mathrm{Co}^{2+}$ and $\mathrm{Sr}^{2+}$ distribution in soil fractions was analyzed as a function of the initial cation concentration in the contaminated soil, and as the function of aging time. The samples were prepared in the following way: $1.000 \mathrm{~g}$ of the soil was firstly equilibrated with $20 \mathrm{~mL}$ of $1 \times 10^{-3}$ or
$10^{-2} \mathrm{~mol} \mathrm{~L}^{-1}$ cation solutions, for $1 \mathrm{~h}$ or 30 days. The suspensions were agitated on the overhead shaker, at constant speed $(10 \mathrm{rpm})$. Subsequently, liquid phase was separated by centrifugation, and the soil residues were allowed to dry at room temperature. Such samples were subjected to sequential extraction, following a modified Tessier procedure (Tessier et al. 1979). In the applied procedure, $\mathrm{Co}^{2+}$ and $\mathrm{Sr}^{2+}$ were partitioned into six operationally defined fractions: water soluble $\left(\mathrm{F}_{0}\right)$, exchangeable $\left(\mathrm{F}_{1}\right)$, bound to carbonates $\left(\mathrm{F}_{2}\right)$, bound to iron and manganese oxides $\left(\mathrm{F}_{3}\right)$, bound to organic matter $\left(\mathrm{F}_{4}\right)$ and residual $\left(\mathrm{F}_{5}\right)$. The summarized procedure is shown in Table 1.

The deviation from the Tessier's original partitioning scheme consists of the addition of water soluble fraction and alteration of the conditions for the extraction of residual phase. The digestion in $6 \mathrm{M} \mathrm{HCl}$ (Table 1) was applied for determination of metal fraction bound to acid soluble residue (Polić and Pfendt 1992; Petrović et al. 2009), as most of the crystalline oxides are dissolved by this procedure, except some types of silicate minerals.

\section{Desorption experiments}

Firstly, $\mathrm{Co}^{2+}$ and $\mathrm{Sr}^{2+}$ ions were sorbed onto soil under the following conditions: solid/liquid ratio $=1 \mathrm{~g} / 20 \mathrm{~mL}$, initial cation concentration $1.5 \times 10^{-3} \mathrm{~mol} \mathrm{~L}^{-1}$, initial $\mathrm{pH}$ 5.7 and equilibration time 1 day. After centrifugation and filtration, metal concentration in liquid phases was measured and sorbed amounts were calculated. The solid residues were dried in air. Desorption of pollutants was investigated by adding $20 \mathrm{~mL}$ of different leaching media and mixing with contaminated soil residues, for $1 \mathrm{~h}$. Variously concentrated $\mathrm{HCl}$ solutions were applied (0.0001, 0.001 and $\left.0.01 \mathrm{~mol} \mathrm{~L}^{-1}\right)$, in order to test the effect of $\mathrm{pH}$ on cation desorption. The influence of the competitive cations $\mathrm{Ca}^{2+}$ was studied as a function of $\mathrm{CaCl}_{2}$ concentration $\left(0.05\right.$ and $\left.0.1 \mathrm{~mol} \mathrm{~L}^{-1}\right)$ and initial solution pH (2 and 5). Furthermore, organic ligands were tested as leaching agents, disodium ethylenediaminetetraacetic acid ( $\mathrm{Na}_{2}$ EDTA), citric acid (CA) and tartaric acid (TA), at various concentrations $\left(0.05\right.$ and $\left.0.1 \mathrm{~mol} \mathrm{~L}^{-1}\right)$ and their natural $\mathrm{pH}$. Experiments were conducted in duplicate. Desorbed amounts of $\mathrm{Co}^{2+}$ and $\mathrm{Sr}^{2+}$ were measured, and desorption efficiencies were calculated.

\section{Results and discussion}

\section{Kinetics of $\mathrm{Co}^{2+}$ and $\mathrm{Sr}^{2+}$ sorption by soil}

The amounts of $\mathrm{Co}^{2+}$ and $\mathrm{Sr}^{2+}$ sorbed onto soil versus contact time are presented in Fig. 1. 
Table 1 Sequential extraction procedure applied in this study

\begin{tabular}{|c|c|c|}
\hline & Fraction & Experimental procedure \\
\hline $\mathrm{F}_{0}$ & Water soluble & $10 \mathrm{~mL}$ distilled water, room temperature, $1 \mathrm{~h}$, continuous agitation \\
\hline $\mathrm{F}_{1}$ & Exchangeable & $8 \mathrm{~mL} 1 \mathrm{M} \mathrm{MgCl}_{2}(\mathrm{pH} 7.0)$, room temperature, $1 \mathrm{~h}$, continuous agitation \\
\hline $\mathrm{F}_{2}$ & Bound to carbonates & $8 \mathrm{~mL} 1 \mathrm{M} \mathrm{NaOAc}(\mathrm{pH}=5$, adjusted with $\mathrm{HOAc})$, room temperature, $5 \mathrm{~h}$, continuous agitation \\
\hline $\mathrm{F}_{3}$ & $\begin{array}{l}\text { Bound to iron and manganese } \\
\text { oxides }\end{array}$ & $20 \mathrm{~mL} 0.04 \mathrm{M} \mathrm{NH}_{2} \mathrm{OH} \cdot \mathrm{HCl}$ in $25 \%(\mathrm{v} / \mathrm{v}) \mathrm{HOAc}, 6 \mathrm{~h}, 96 \pm 3{ }^{\circ} \mathrm{C}$, occasional agitation \\
\hline $\mathrm{F}_{4}$ & Bound to organic matter & $\begin{array}{l}\text { (1) } 3 \mathrm{~mL} 0.02 \mathrm{M} \mathrm{HNO}_{3} \text { and } 5 \mathrm{~mL} 30 \% \mathrm{H}_{2} \mathrm{O}_{2}\left(\mathrm{pH}=2 \text {, adjusted with } \mathrm{HNO}_{3}\right), 2 \mathrm{~h}, 85 \pm 2{ }^{\circ} \mathrm{C} \text {, } \\
\text { occasional agitation } \\
\text { (2) } 3 \mathrm{~mL} 30 \% \mathrm{H}_{2} \mathrm{O}_{2}\left(\mathrm{pH}=2 \text {, adjusted with } \mathrm{HNO}_{3}\right), 3 \mathrm{~h}, 85 \pm 2{ }^{\circ} \mathrm{C} \text {, intermittent agitation } \\
\text { (3) } 5 \mathrm{~mL} 3.2 \mathrm{M} \mathrm{NH}_{4} \mathrm{OAc} \text { in } 20 \% \text { (v/v) } \mathrm{HNO}_{3} \text {, sample dilute to } 20 \mathrm{~mL} \text {, room temperature, } 30 \mathrm{~min} \text {, } \\
\text { continuous agitation }\end{array}$ \\
\hline $\mathrm{F}_{5}$ & Residual & $50 \mathrm{~mL} 6 \mathrm{M} \mathrm{HCl}$ for $9 \mathrm{~h}$ at $85 \pm 2{ }^{\circ} \mathrm{C}$ \\
\hline
\end{tabular}

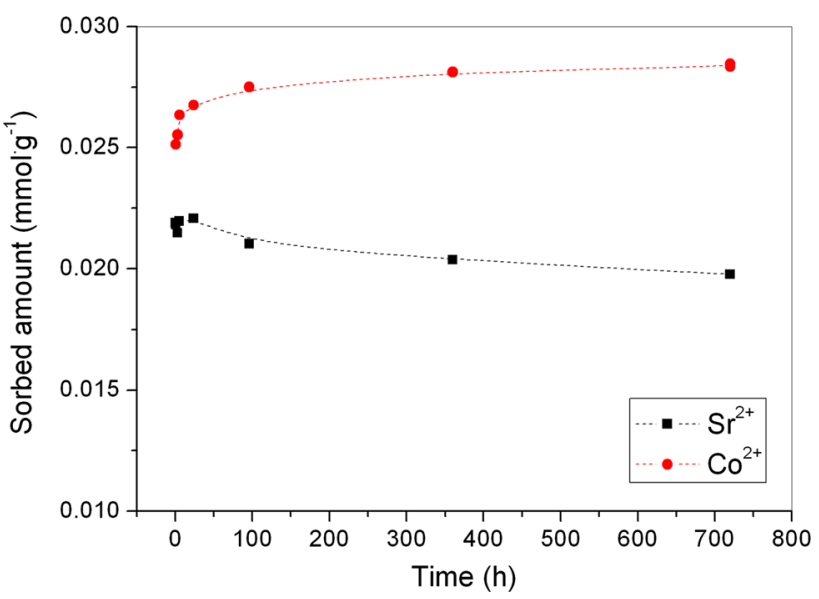

Fig. 1 Kinetics of $\mathrm{Sr}^{2+}$ and $\mathrm{Co}^{2+}$ sorption onto soil. Initial cation concentration $1.5 \times 10^{-3} \mathrm{~mol} \mathrm{~L}^{-1}$, initial $\mathrm{pH} 5.7$, soil/solution ratio $1 \mathrm{~g} / 20 \mathrm{~mL}$

Curve characteristic for $\mathrm{Co}^{2+}$ sorption exhibited continuous increase which was the most evident in the first $96 \mathrm{~h}$. Sorption processes that slowly increase with time are understood to be controlled by the mechanisms such as micropore diffusion and surface nucleation/precipitation reactions (Sparks 2003). $\mathrm{Sr}^{2+}$ sorption kinetics was quite different. At the very beginning, $\mathrm{Sr}^{2+}$ removal from solution was faster with respect to $\mathrm{Co}^{2+}$, and the maximum sorption was registered after $24 \mathrm{~h}$ of contact. Afterward, $\mathrm{Sr}^{2+}$ sorption curve declined, i.e., the desorption process took place. The changes of $\mathrm{Co}^{2+}$ and $\mathrm{Sr}^{2+}$ sorbed amounts were evident during the first $96 \mathrm{~h}$, while for longer contact times (up to 30 days), the differences were less pronounced. It was assumed that for both investigated cations, quasi-equilibrium was reached after 4 days. Sorption capacities of soil toward $\mathrm{Co}^{2+}$ and $\mathrm{Sr}^{2+}$ on quasi-equilibrium were found to be 0.28 and $0.21 \mathrm{mmol} \mathrm{g}^{-1}$, respectively. Lower capacities and higher sorption rates for $\mathrm{Sr}^{2+}$ with respect to $\mathrm{Co}^{2+}$ were reported for other soil types (Park et al. 1994), indicating formation of different types of surface complexes between the soil constituents and investigated cations. As earth-alkaline cation, $\mathrm{Sr}^{2+}$ forms weaker complexes with both mineral surfaces and organic components of the soil. Decrease in $\mathrm{Sr}^{2+}$ sorption, which was recorded after $24 \mathrm{~h}$, may be caused by surface dissolution/precipitation reactions of soil constituents (especially calcite), release of loosely attached $\mathrm{Sr}^{2+}$ ions and competition between $\mathrm{Sr}^{2+}$ and other aqueous species (Bunde et al. 1997).

\section{The pH effect onto $\mathrm{Co}^{2+}$ and $\mathrm{Sr}^{2+}$ sorption onto soil}

Solution $\mathrm{pH}$ is an important parameter for cation sorption by soils, as it governs the dissolution/precipitation reactions and hydrolysis of free active cites on the soil surface as well as the distribution of the sorbate ionic species in the solution. The results of sorption experiments performed at different initial $\mathrm{pH}$ are given in Fig. 2a.

Both $\mathrm{Co}^{2+}$ and $\mathrm{Sr}^{2+}$ sorption increased with the increase in initial $\mathrm{pH}$ in the acidic media ( $\mathrm{pH}$ range 1.5-4), while remaining constant at higher investigated $\mathrm{pH}$. For the same initial $\mathrm{pH}$, sorbed amounts of $\mathrm{Co}^{2+}$ were always higher than those of $\mathrm{Sr}^{2+}$. However, sorption of cations onto soil was strongly suppressed under acidic conditions, thus the differences between $\mathrm{Sr}^{2+}$ and $\mathrm{Co}^{2+}$ sorption capacities were less evident.

Initially, the increase in initial $\mathrm{pH}$ provoked rapid increase in final $\mathrm{pH}$, whereas at initial $\mathrm{pH}>3$, the plateaus were reached (Fig. 2b) and final pH values remained constant $\left(\sim 7.7\right.$ and $\sim 7.5$, respectively, after sorption of $\mathrm{Sr}^{2+}$ and $\mathrm{Co}^{2+}$ ions). It is important to notice that final $\mathrm{pH}$ values measured after sorption of $\mathrm{Co}^{2+}$ were always slightly lower, suggesting higher degree of complexation with free hydroxyl groups and formation of inner-sphere surface complexes. The overall buffering properties of the soil are in correlation with buffering properties of its 


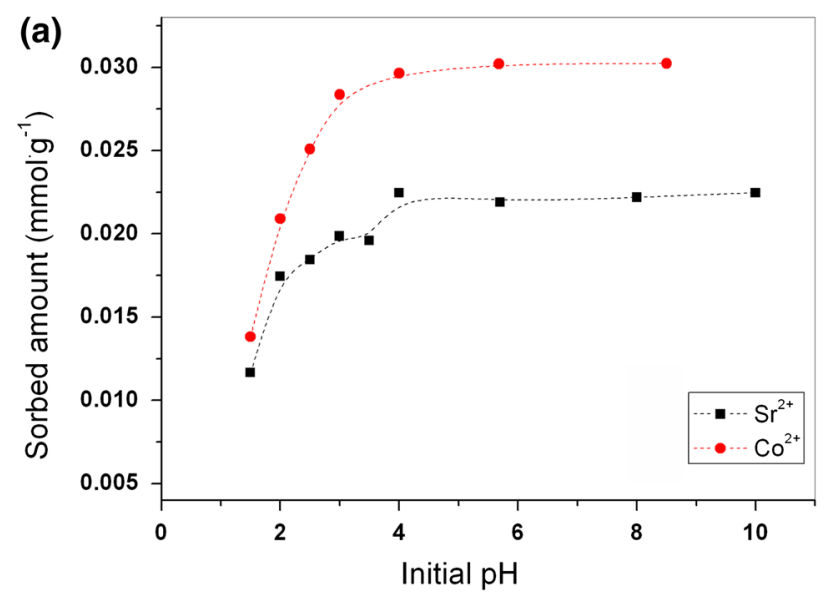

(b)

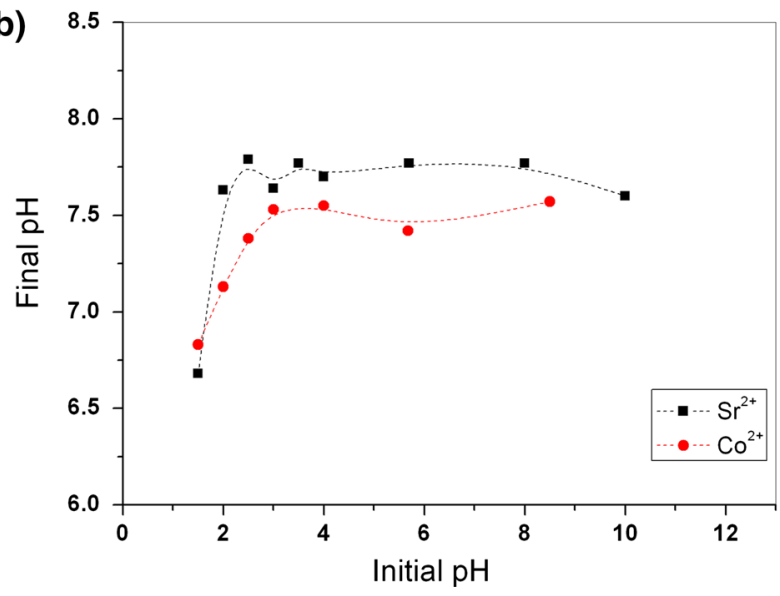

Fig. 2 Effect of initial solution $\mathrm{pH}$ on a $\mathrm{Sr}^{2+}$ and $\mathrm{Co}^{2+}$ amounts sorbed by the soil and $\mathbf{b}$ final solution $\mathrm{pH}$. Initial cation concentration $1.5 \times 10^{-3} \mathrm{~mol} \mathrm{~L}^{-1}$, soil/solution ratio $1 \mathrm{~g} / 20 \mathrm{~mL}$, equilibration time $96 \mathrm{~h}$

constituents. Quartz and muscovite, which are the most abundant crystalline phases detected in the mineralogical composition of the investigated soil (Dimović et al. 2013), exhibit rather low points of zero charge $(<2$ (Cakara et al. 2009) and 2-4 (Kosmulski 2014), respectively), as well as micas 2-3.5 (Kosmulski 2014), kaolinite 4.5-5 (Sposito 1984) and albite $\sim 2$ (Kosmulski 2011). Therefore, kyanite [7.8 (Fuerstenau and Raghavan 1980)] and especially calcite (8-9.5 (Somasundaran and Agar 1967)) are responsible for large buffering capacity and weakly alkaline reaction of soil with water. Under such conditions, various aluminosilicate fractions carry a negative surface charge, which promotes cation sorption.

\section{$\mathrm{Co}^{2+}$ and $\mathrm{Sr}^{2+}$ sorption isotherms}

The obtained relationships between the amounts of cations sorbed by the soil and the residual metal concentrations in liquid phases with increasing metal concentration are given in Fig. 3.

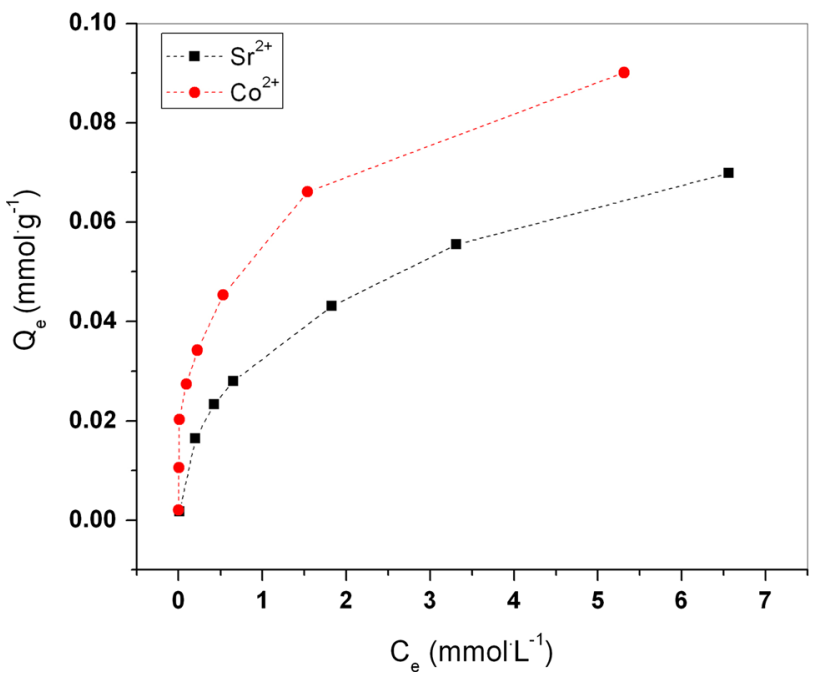

Fig. 3 Isotherms of $\mathrm{Co}^{2+}$ and $\mathrm{Sr}^{2+}$ sorption by soil. Initial solution $\mathrm{pH}$ 5.7, soil/solution ratio $1 \mathrm{~g} / 20 \mathrm{~mL}$, equilibration time $96 \mathrm{~h}$

The isotherms of $\mathrm{Co}^{2+}$ and $\mathrm{Sr}^{2+}$ sorption onto soil exhibited shapes of high affinity $(\mathrm{H})$ and favorable (L) type, respectively (Giles et al. 1974). Experimentally obtained data were fitted using linear forms of Langmuir and Freundlich equations (Table 2), where $q_{\mathrm{m}}\left(\mathrm{mmol} \mathrm{g}^{-1}\right)$ represents the maximum sorption capacity, $K_{\mathrm{L}}\left(\mathrm{dm}^{3} \mathrm{mmol}^{-1}\right)$ is the Langmuir constant related to the energy of adsorption, whereas $K\left(\mathrm{mmol}^{1-\mathrm{n}} \mathrm{dm}^{3 \mathrm{n}} \mathrm{g}^{-1}\right)$ and $n$ are the Freundlich constants related to the capacity and intensity of the sorption process.

Maximum sorption capacities, calculated from Langmuir correlation, were $0.077 \mathrm{mmol} \mathrm{g}^{-1}$ for $\mathrm{Sr}^{2+}$ and $0.092 \mathrm{mmol} \mathrm{g}^{-1}$ for $\mathrm{Co}^{2+}$. Higher capacity of the soil for sorption of $\mathrm{Co}^{2+}$ ions was also approved by higher $\mathrm{K}$ value obtained using Freundlich model. Calculated $R$ values were high for both models.

The equilibrium solutions' $\mathrm{pH}$ values and the quantities of released $\mathrm{Ca}^{2+}$ ions were also measured as a function of cation sorbed amounts (Fig. 4a and b).

Under experimental conditions applied in the sorption experiments, the rise of solution $\mathrm{pH}$ from initial $\mathrm{pH} 5.7$ to final 7.7 was recorded in the absence of $\mathrm{Co}^{2+}$ and $\mathrm{Sr}^{2+}$ (blank experiment), and it can be ascribed to calcite dissolution. Furthermore, the higher the sorbed amount of cations - the lower solution $\mathrm{pH}$ was observed. $\mathrm{pH}$ declined down to 7.2 and to 7.0 after $\mathrm{Sr}^{2+}$ and $\mathrm{Co}^{2+}$ sorption, respectively, signifying liberation of surface $\mathrm{H}^{+}$ions.

The quantities of $\mathrm{Ca}^{2+}$ ions released from soil surface during the sorption process are compared in Fig. 4b. In order to obtain sorption-related $\mathrm{Ca}^{2+}$ fractions, presented concentrations of $\mathrm{Ca}^{2+}$ were calculated by subtracting the amounts of $\mathrm{Ca}^{2+}$ released in the blank solution from the total amounts of $\mathrm{Ca}^{2+}$ measured after sorption experiments. It can be noted that relationships between released $\mathrm{Ca}^{2+}$ 
Table 2 Parameters of Langmuir and Freundlich models for $\mathrm{Co}^{2+}$ and $\mathrm{Sr}^{2+}$ sorption by soil

\begin{tabular}{|c|c|c|c|c|c|c|}
\hline \multirow[t]{2}{*}{ Cation } & \multicolumn{3}{|c|}{$\begin{array}{l}\text { Langmuir equation } \\
C_{\mathrm{e}} / Q_{\mathrm{e}}=1 / q_{\mathrm{m}} K_{\mathrm{L}}+C_{\mathrm{e}} / q_{\mathrm{m}}\end{array}$} & \multicolumn{3}{|c|}{$\begin{array}{l}\text { Freundlich equation } \\
\ln Q_{\mathrm{e}}=\ln K+n \ln C_{\mathrm{e}}\end{array}$} \\
\hline & $K_{\mathrm{L}}$ & $q_{\mathrm{m}}$ & $R$ & $K$ & $n$ & $R$ \\
\hline $\mathrm{Sr}^{2+}$ & $1.02 \pm 0.16$ & $0.077 \pm 0.004$ & 0.990 & $0.030 \pm 0.004$ & $0.58 \pm 0.11$ & 0.979 \\
\hline $\mathrm{Co}^{2+}$ & $4.15 \pm 0.78$ & $0.092 \pm 0.002$ & 0.992 & $0.055 \pm 0.003$ & $0.28 \pm 0.03$ & 0.974 \\
\hline
\end{tabular}

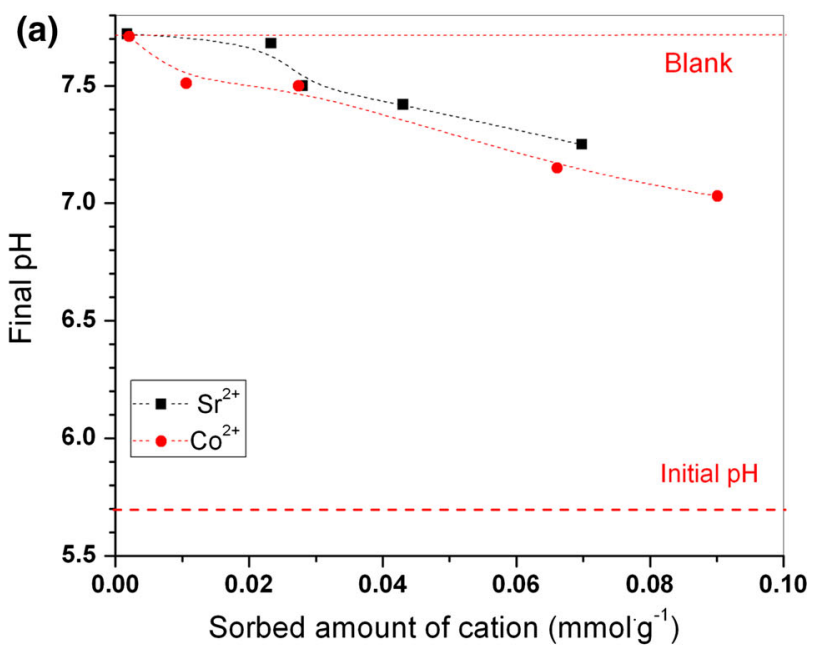

(b)

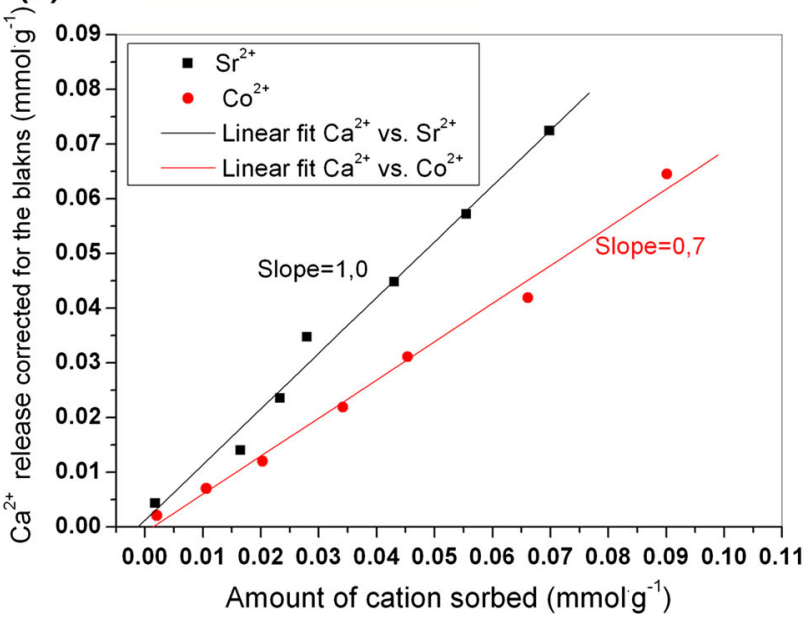

Fig. 4 Relationships between the amounts of $\mathrm{Co}^{2+}$ and $\mathrm{Sr}^{2+}$ cations sorbed and a final $\mathrm{pH}$ values, $\mathbf{b}$ amounts of $\mathrm{Ca}^{2+}$ released. Initial solution $\mathrm{pH}$ 5.7, soil/solution ratio $1 \mathrm{~g} / 20 \mathrm{~mL}$, equilibration time $96 \mathrm{~h}$

and sorbed amounts of investigated cations were linear ( $R=0.99$, for both cations). With the increased overall sorption, the contribution of an ion exchange mechanism and/or calcium-carbonate dissolution followed by $\mathrm{Me}^{2+}$ precipitation increased as well. In addition, higher amounts of $\mathrm{Ca}^{2+}$ were released after sorption of $\mathrm{Sr}^{2+}$. In the entire range of applied $\mathrm{Sr}^{2+}$ concentrations, molar ratio of $1: 1$ was obtained between released $\mathrm{Ca}^{2+}$ and sorbed $\mathrm{Sr}^{2+}$, demonstrating important role of calcite in the $\mathrm{Sr}^{2+}$ sorption mechanism by investigated soil.
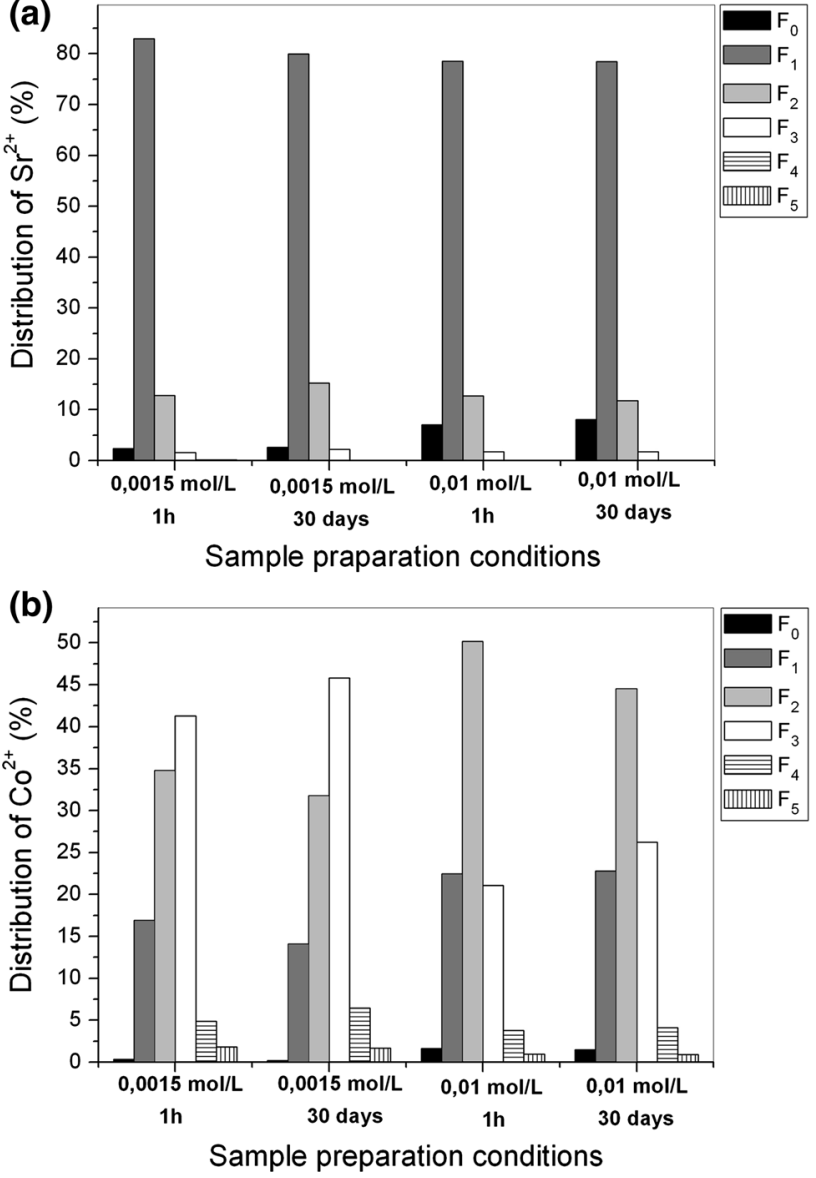

Fig. 5 Influence of cation concentration and aging time on the distribution of $\mathrm{Sr}^{2+}$ (a) and $\mathrm{Co}^{2+}(\mathbf{b})$ in soil fractions: $\mathrm{F}_{0}$ - water soluble, $\mathrm{F}_{1}$ - exchangeable, $\mathrm{F}_{2}$ - bound to carbonates, $\mathrm{F}_{3}$ - bound to iron and manganese oxides, $F_{4}$ - bound to organic matter, $F_{5}-$ residual

\section{Comparison of the $\mathrm{Co}^{2+}$ and $\mathrm{Sr}^{2+}$ distribution in soil fractions}

Various binding fractions of $\mathrm{Co}^{2+}$ and $\mathrm{Sr}^{2+}$ in soil were determined by sequential extraction method, as a function of aging time and starting concentration of cations in the contaminated soil (Fig. 5).

In the original (uncontaminated) sample of investigated soil, $\mathrm{Sr}^{2+}$ ions were found largely in exchangeable (61\%), carbonate $(16 \%)$ and residual phase $(14 \%)$, whereas $\mathrm{Co}^{2+}$ was mainly distributed in moderately reducible $(47 \%)$ and 
residual phase (36\%) (Dimović et al. 2013). After contamination, the distribution of investigated cations changed considerably and the rearrangement to more mobile fractions was obvious.

Strontium was concentrated in exchangeable phase (78-83\%, depending on the sample preparation), and to a much lesser degree in carbonate, water soluble phase and bound to Fe, Mn oxide (Fig. 5a). High mobility of $\mathrm{Sr}^{2+}$ ions and its preferential accumulation in ion exchange sites and carbonate phase were reported in the literature for some other soil types (Jinzhou et al. 1996; Lerouge et al. 2010).

The increased initial metal concentration in the soil have caused further mobility increase, by regrouping of $\mathrm{Sr}^{2+}$ ions from exchangeable to water soluble fraction. On the other hand, prolonged aging time caused only small changes in $\mathrm{Sr}^{2+}$ distribution, i.e., at lower investigated $\mathrm{Sr}^{2+}$ concentration, slight transition from exchangeable to carbonate fraction was recorded. This observation is consistent with the results of radiostrontium mobility investigation in various soils samples, where no retardation of $\mathrm{Sr}^{2+}$ mobility occurred with aging (Rigol et al. 1999; Wallace et al. 2012).

$\mathrm{Co}^{2+}$ ions generally exhibited lower mobility in the soil when compared to $\mathrm{Sr}^{2+}$ (Fig. 5b). They were mainly found in $\mathrm{F}_{3}$ phase, at lower initial rate. With the increase in initial cation concentration, fraction of pollutant in $\mathrm{F}_{3}$ drastically decreased, whereas increased in $\mathrm{F}_{0}, \mathrm{~F}_{1}$ and $\mathrm{F}_{2}$. Carbonate phase took over the role of the dominant $\mathrm{Co}^{2+}$ reservoir, and the overall mobility of $\mathrm{Co}^{2+}$ in the soil increased. Aging time did not influence the content of metal in water soluble fraction; however, $\mathrm{Co}^{2+}$ redistribution from $\mathrm{F}_{2}$ to $\mathrm{F}_{3}$ fraction was noticed after one month of aging for both investigated initial concentrations. Influence of aging time on $\mathrm{Co}^{2+}$ transition from more to less bioavailable fractions can be explained by slow diffusion of $\mathrm{Co}^{2+}$ from outersphere to inner-sphere complexes with $\mathrm{Fe}, \mathrm{Mn}$ oxides. The increasing fixation of $\mathrm{Cu}, \mathrm{Cr}, \mathrm{Ni}$ and $\mathrm{Zn}$ in $\mathrm{F}_{3}$ and $\mathrm{F}_{5}$ fractions, after aging for three years, was also detected (Keppler and Brümmer 1997). Correspondingly, it was reported that sorbed $\mathrm{Pb}$ and $\mathrm{Cd}$ transferred from the loosely bounded to strongly bounded soil fractions with increasing residence time (Lim et al. 2002).

The observed metal distributions are in agreement with the results of sorption experiments. Furthermore, literature data on the principal mechanisms of cation sorption by various minerals show that $\mathrm{Sr}^{2+}$ was principally sorbed by ion exchange, outer-sphere complex formation and surface precipitation/coprecipitation with carbonates, whereas $\mathrm{Co}^{2+}$ by inner-sphere surface complexes formation, ion exchange and precipitation mechanisms (Brown and Parks 2001).

\section{$\mathrm{Co}^{2+}$ and $\mathrm{Sr}^{2+}$ desorption}

Desorption studies were conducted to estimate the reversibility of sorption processes in various leaching solutions, with implications to soil decontamination. Starting concentrations of cations in the contaminated soil were $0.027 \mathrm{mmolCo}^{2+} \mathrm{g}^{-1}$ and $0.022 \mathrm{mmolSr}^{2+} \mathrm{g}^{-1}$, whereas the percentages of desorbed cations are presented in Fig. 6 .

Amounts of desorbed metals were strongly dependent on the leaching solution composition. $\mathrm{Sr}^{2+}$ was generally more sensitive than $\mathrm{Co}^{2+}$ to acidic solutions, i.e., desorption linearly increased from 20 to $93 \%$, with the increase in acid concentration in the investigated range (Fig. 6a). Conversely, desorption of $\mathrm{Co}^{2+}$ was inefficient at lower $\mathrm{HCl}$ concentrations, while abruptly increased to $72 \%$ in $0.1 \mathrm{~mol} \mathrm{~L}^{-1} \mathrm{HCl}$.

The competitive effect of $\mathrm{Ca}^{2+}$ cations was examined at two different concentrations of $\mathrm{CaCl}_{2}$ and initial $\mathrm{pH}$ (Fig. 6b). Desorption of $\mathrm{Sr}^{2+}$ was found to be practically independent on the applied $\mathrm{Ca}^{2+}$ concentrations and $\mathrm{pH}$. Yet, desorption was very high and relatively constant (86-88 \%), so it can be assumed that under applied experimental conditions (soil/solution ratio, contact time, etc.) maximum was achieved using any of the prepared solutions. $\mathrm{Co}^{2+}$ desorption was also unaffected by increased $\mathrm{Ca}^{2+}$ content in the leaching solution, nevertheless, leaching was more efficient at $\mathrm{pH} 2(54 \%)$ than at $\mathrm{pH} 5.5$ $(38 \%)$. Joint effects of acid and $\mathrm{Ca}^{2+}$ can be observed by comparing desorption efficiencies at the same initial $\mathrm{pH}$ (2), without (Fig. 6a) and with competitive $\mathrm{Ca}^{2+}$ cations (Fig. 6b). The results are consistent with the previous findings that sorption of $\mathrm{Sr}^{2+}$ by soil was largely suppressed in the presence of competing cations such as $\mathrm{Ca}^{2+}$ (Bunde et al. 1997), as well as that sorption of trace $\mathrm{Sr}^{2+}$ amounts onto calcareous soil was completely reversible in $\mathrm{Ca}^{2+}$-containing solution (Xiongxin and Zuy 1999).

The efficiency of various organic complexants is presented in Fig. 6c. Desorption of $\mathrm{Sr}^{2+}$ and $\mathrm{Co}^{2+}$ varied in ranges 55-93 and 52-89\%, respectively. Different desorption efficiencies of $\mathrm{Co}^{2+}$ and $\mathrm{Sr}^{2+}$ are influenced by different stability constants of resulting complexes, as well as by dissimilar accessibility of metals in the soil. $\mathrm{Sr}^{2+}$ desorption decreased in the order $\mathrm{CA}>\mathrm{Na}_{2}$ EDTA $>$ TA and $\mathrm{Na}_{2}$ EDTA $>\mathrm{CA} \geq \mathrm{TA}$, for lower and higher ligand concentration, respectively. On the other hand, selectivity sequence for $\mathrm{Co}^{2+}$ was $\mathrm{CA} \geq \mathrm{TA}>\mathrm{Na}_{2}$ EDTA. Desorption was enhanced using more concentrated $\mathrm{CA}$, while practically unaffected by changes in $\mathrm{Na}_{2}$ EDTA and TA concentrations. Washing of sandy loam contaminated with divalent metals $(\mathrm{Cu}, \mathrm{Ni}, \mathrm{Zn}, \mathrm{Cd}$ and $\mathrm{Pb})$ revealed that desorption commonly decreased in the order EDTA $>$ CA > TA (Wuana et al. 2010). In the mentioned study, 
Fig. 6 Efficiencies of $\mathrm{Sr}^{2+}$ and $\mathrm{Co}^{2+}$ desorption from contaminated soil using: $\mathbf{a}$ acidic solutions, $\mathbf{b}$ competitive cations, c organic ligands $\left(\mathrm{Na}_{2}\right.$ EDTA-disodium ethylenediaminetetraacetic acid, $\mathrm{CA}$ - citric acid, TA-tartaric acid). The bars represent average values of duplicate experiments
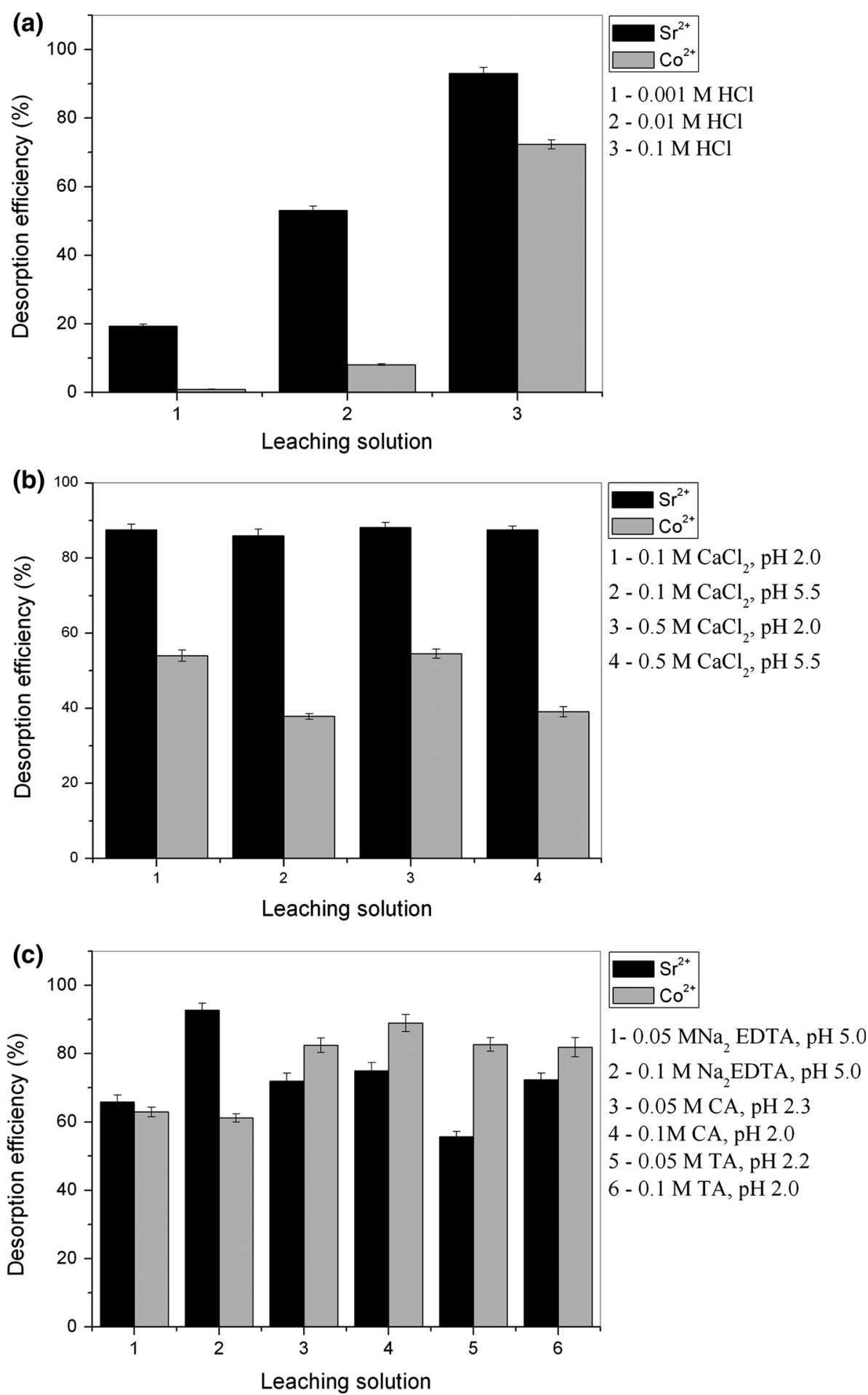

reagent concentration was intentionally set at $0.05 \mathrm{M}$, to maintain the $\mathrm{pH}$ of the soil-chelant mixture low enough for metals to exist as ions. The superior effect of EDTA was confirmed by sequential extraction analysis of washed soil samples which indicated that EDTA removed metals from all non-residual fractions (Wuana et al. 2010). Low position of $\mathrm{Na}_{2}$ EDTA in the selectivity sequence obtained for $\mathrm{Co}^{2+}$ desorption in the present study may be caused by higher initial $\mathrm{pH}$ of this reagent with respect to $\mathrm{CA}$ and $\mathrm{TA}$ solutions. $\mathrm{Sr}^{2+}$ desorption was not suppressed by $\mathrm{pH}$ factor as much as $\mathrm{Co}^{2+}$, most likely due to its elevated accessibility in the soil. 


\section{Possible soil remediation methods}

In case of accidental soil contamination, the final choice of appropriate remediation method would require consideration of numerous factors such as type and level of contamination, physicochemical characteristics of the soil, depth and total amount of soil to be treated, mobility of radionuclides, future purpose of the site and available budget. (IAEA 1997, 1999). According to their treatment mechanism, remediation technologies can roughly be divided to physical, chemical, biological, electrical and thermal. These methods can be additionally subdivided into in situ and ex situ processes (Peters 1999). In situ remediation require no excavation and transport of the contaminated soil, thus it is generally less expensive. Technologies such as in situ vitrification, containment and immobilization aim at converting contaminated soil into a durable and leach resistant form. However, significant increase in time needed to achieve the desired effect, questionable uniformity of the treatment and difficult monitoring of the effects are the major drawbacks of such methods. Conversely, excavation of contaminated soil and its subsequent treatment usually makes ex situ techniques more complicated and costly, but the bulk of contaminants are permanently removed from the soil (Peters 1999).

Although the applicability of a certain method has to be evaluated on a case-by-case basis, some guidelines are derived from research studies and practical experience. Soils in which contaminants are mainly bonded in exchangeable, carbonate and reducible phase are designated as suitable for soil washing, whereas removal of contaminants from organically and residually bound fraction would not be economical and maybe not feasible (Peters 1999; Kaplan and Serkiz 2001; Mulligan et al. 2001). Due to low mobility and low bioavailability, extraction of such pollutants may not be necessary. Application of solidification/immobilization methods would assure the additional stabilization of such pollutants.

Relatively high mobility of $\mathrm{Sr}^{2+}$ and $\mathrm{Co}^{2+}$ cations observed in this study points toward chemical extraction as a promising cleanup method. This was also confirmed by the results of preliminary desorption study. Effectiveness of the extraction processes can be additionally improved by optimizing reagent type and concentration, soil/solution ratio, $\mathrm{pH}$, contact time, mixing, temperature, etc. The use of acid- or salt-containing solutions would be more justified from the viewpoint of treatment cost and subsequent extract managing. Such extracts can be treated by a variety of methods available for liquid radioactive waste (sorption, electrochemical techniques, ion exchange, membrane technologies, etc.), to concentrate radionuclides for their final disposal. Complexing agents keep the contaminants in a solution, in a stable form. For radionuclide recovery, complexing agents must be degraded, or, better yet, regenerated in order to keep treatment costs at a reasonable level (Lim et al. 2005). In practical implementation, chemical extractions are typically carried out ex situ, whereas after treatment and rinsing with water, soil is returned to the site (Peters 1999). Large-scale applications of chemical extraction are costly, and the properties of the processed soil can be deteriorated and inappropriate for revegetation and on-site disposal (Dermont et al. 2008). Nevertheless, if the chemical reagents are recycled or not hazardous, chemically enhanced soil washing can become cost-effective (Dermont et al. 2008).

Alternatively, if the technical or economical problems make chemical extraction unfeasible, in situ immobilization technologies may be considered. Remediation based on physical separation methods is suitable for particulate forms of metals and generally not appropriate for treating sorbed forms of cations (Dermont et al. 2008), as was the case in this study.

\section{Conclusion}

The aim of the present study was to evaluate sorption/ desorption properties of $\mathrm{Co}^{2+}$ and $\mathrm{Sr}^{2+}$ in the soil and to make recommendations on possible remediation techniques based on the cations mobility. The uncontaminated soil sample was taken from the area of Vinča Institute of Nuclear sciences, where radioactive waste processing and interim storage facilities are located. Sorption of cations was investigated as a function of aging time, initial cation concentration and solution $\mathrm{pH}$, whereas desorption tests included both sequential and bulk leaching tests in different aqueous media. According to the batch kinetic and isotherm studies, $\mathrm{Sr}^{2+}$ sorption was initially faster but with lower maximum sorption capacity compared to $\mathrm{Co}^{2+}$. Correlations between the amount of $\mathrm{Ca}^{2+}$ and $\mathrm{H}^{+}$ions released during sorption of $\mathrm{Co}^{2+}$ and $\mathrm{Sr}^{2+}$ indicated their different sorption mechanisms. Added $\mathrm{Sr}^{2+}$ ions end up predominantly in exchangeable fraction, whereas $\mathrm{Co}^{2+}$ distributed largely between carbonate phase and $\mathrm{Fe}, \mathrm{Mn}$ oxides. Increasing metal concentration in the soil enhanced mobility of both cations, while increasing aging time provoked relocation of $\mathrm{Co}^{2+}$ from carbonate to $\mathrm{Fe}, \mathrm{Mn}$ oxide fraction. Desorption studies revealed that acidic media and solutions of competing cations $\left(\mathrm{Ca}^{2+}\right)$ induced more effective release of $\mathrm{Sr}^{2+}$ from the soil, while complexing agents such as citric and tartaric acids used at their natural $\mathrm{pH}(\sim 2)$ leached more $\mathrm{Co}^{2+}$ than $\mathrm{Sr}^{2+}$. The best results were obtained with $0.1 \mathrm{M} \mathrm{HCl}$ and $0.1 \mathrm{M} \mathrm{Na}_{2}$ EDTA at $\mathrm{pH}$ 5 for $\mathrm{Sr}^{2+}$ ( $\sim 93 \%$ recovery) and with $0.1 \mathrm{M}$ citric acid at pH 2 for $\mathrm{Co}^{2+}$ (89\% recovery). Results indicate that chemical extraction with selective reagents may be 
considered as a remediation method for $\mathrm{Sr}^{2+}-$ and $\mathrm{Co}^{2+}$ contaminated soil.

Acknowledgments This work was supported by the Ministry of Education, Science and Technological Development of the Republic of Serbia (Project III43009).

\section{References}

Brown GE, Parks GA (2001) Sorption of trace elements on mineral surfaces: modern perspectives from spectroscopic studies and comments on sorption in the marine environment. Int Geol Rev 43:963-1074

Bunde RL, Rosentreter JJ, Liszewski MJ, Hemming CH, Welhan J (1997) Effects of calcium and magnesium on strontium distribution coefficients. Environ Geol 32:219-229

Cakara D, Kobayashi M, Skarba M, Borkovec M (2009) Protonation of silica particles in the presence of a strong cationic polyelectrolyte. Colloids Surf A 339:20-25

Dermont G, Bergeron M, Mercier G, Richer-Laflèche M (2008) Soil washing for metal removal: a review of physical/chemical technologies and field applications. J Hazard Mater 152:1-31

Dimović S, Smičiklas I, Šljivić-Ivanović M, Dojčinović B (2013) Speciation of ${ }^{90} \mathrm{Sr}$ and other metal cations in artificially contaminated soils: the influence of bone sorbent addition. J Soils Sediment 13:383-393

Fuerstenau DW, Raghavan S (1980) In: Proceedings XII international mineral processing congress, vol II. Nacional Publicacoes \& Pubicadado, Sao Paulo

Giles CH, D'Silva AP, Easton IA (1974) A general treatment and classification of the solute adsorption isotherm part. II. Experimental interpretation. J Colloid Interface Sci 47:766-778

Harmsen RW, Schulz WW (1998) Best-basis estimates of solubility of selected radionuclide in hanford single-shell tank sludge. HNF-3271. Lockheed Martin Hanford Corporation, Richland

Hsu C-N, Liu D-C, Chuang C-L (1994) Equilibrium and kinetic sorption behaviors of cesium and strontium in soils. Appl Radiat Isotopes 45:981-985

IAEA (1997) Technologies for in situ immobilization and isolation of radioactive wastes at disposal and contaminated sites. IAEATECDOC-972, Vienna

IAEA (1999) Technologies for remediation of radioactively contaminated sites. IAEA-TECDOC-1086, Vienna

Jinzhou D, Wenming D, Xiangke W, Zuyi T (1996) Sorption and desorption of radiostrontium on calcareous soil and its solid components. J Radioanal Nucl Chem 203:31-36

Kamel NHM (2010) Adsorption models of ${ }^{137} \mathrm{Cs}$ radionuclide and $\mathrm{Sr}$ (II) on some Egyptian soils. J Environ Radioact 101:297-303

Kaplan DI, Serkiz SM (2001) Quantification of thorium and uranium sorption to contaminated sediments. J Radioanal Nucl Chem 248:529-535

Keppler J, Brümmer GW (1997) Schwermetall-Bindungsformen in Böden und ihre Veränderung über die Zeit - Ergebnisse eines Inkubationsversuches. Mitteilungen der Deutschen Bodenkundlichen Gesellschaft 85:255-258 (in German)

Kosmulski M (2011) The pH-dependent surface charging and points of zero charge V. Update. J Colloid Interface Sci 353:1-15

Kosmulski M (2014) The $\mathrm{pH}$ dependent surface charging and points of zero charge. VI. Update. J Colloid Interface Sci 426:209-212

Lavrentyeva GV (2014) Characteristic of pollution with groundwater in flow ${ }^{90} \mathrm{Sr}$ natural waters and terrestrial ecosystems near a radioactive waste storage. J Environ Radioact 135:128-134
Lerouge C, Gaucher EC, Tournassat C, Negrel P, Crouzet C, Guerrot C, Gautier A, Michel P, Vinsot A, Buschaert S (2010) Strontium distribution and origins in a natural clayey formation (CallovianOxfordian, Paris Basin, France): a new sequential extraction procedure. Geochim Cosmochim Acta 74:2926-2942

Lim TT, Tay JH, Teh CI (2002) Contamination time effect on lead and cadmium fractionation in a tropical coastal clay. $\mathrm{J}$ Environ Qual 31:806-812

Lim TT, Chui PC, Goh KH (2005) Process evaluation for optimization of EDTA use and recovery for heavy metal removal from a contaminated soil. Chemosphere 58:1031-1040

Mulligan CN, Yong RN, Gibbs BF (2001) Remediation technologies for metal-contaminated soils and groundwater: an evaluation. Eng Geol 60:193-207

NCRP (National Council on Radiation Protection \& Measurements) (1991) Some aspects of strontium radiobiology. NCRP report no. 110. Bethesda

Park CK, Hahn PS, Park HH (1994) Differentiation of sorptive bindings of some radionuclide with sequential chemical extractions in sendstones. J Korean Nucl Soc 26:461-470

Peters R (1999) Chelant extraction of heavy metals from contaminated soils. J Hazard Mater 66:151-210

Petrović D, Todorović M, Manojlović D, Krsmanović VD (2009) Speciations of trace metals in the accumulation Bogovina on the Crni Timok River. Pol J Environ Stud 18:873-884

Polić P, Pfendt P (1992) Iron and manganese oxides as dominant nickel substrates in the Novi Beograd aquifer. J Serb Chem Soc 57:697-703

Rigol A, Roig M, Vidal M, Rauret G (1999) Sequential extractions for the study of radiocesium and radiostrontium dynamics in mineral and organic soils from Western Europe and Chernobyl areas. Environ Sci Technol 33:887-895

Salbu B, Lind OC, Skipperud L (2004) Radionuclide speciation and its relevance in environmental impact assessments. J Environ Radioactiv 74:233-242

Singh A, Prasad SM (2014) Remediation of heavy metal contaminated ecosystem: an overview on technology advancement. Int $\mathbf{J}$ Environ Sci Technol. doi:10.1007/s13762-014-0542-y

Solecki J (2005) Investigation of ${ }^{85} \mathrm{Sr}$ adsorption on selected-soils of different horizons. J Environ Radioactiv 82:303-320

Somasundaran P, Agar GE (1967) The zero point of charge of calcite. J Colloid Interface Sci 24:433-440

Sparks DL (2003) Environmental soil chemistry. Academic Press, San Diego

Sposito G (1984) The surface chemistry of soils. Oxford University Press, New York

Tessier A, Campbell PGC, Bisson M (1979) Sequential extraction procedure for the speciation of articulate trace metals. Anal Chem 51:844-860

USDOE (1996) Evaluation of cobalt mobility in soils from thr Nevada test site. Department of Energy, Reno

Wallace SH, Shaw S, Morris K, Small JS, Fuller AJ, Burke IT (2012) Effect of groundwater $\mathrm{pH}$ and ionic strength on strontium sorption in aquifer sediments: implications for ${ }^{90} \mathrm{Sr}$ mobility at contaminated nuclear sites. Appl Geochem 27:1482-1491

Wuana RA, Okieimen FE, Imborvungu JA (2010) Removal of heavy metals from a contaminated soil using organic chelating acids. Int J Environ Sci Tech 7:485-496

Xiongxin D, Zuy T (1999) Effect of carbonates on sorption and migration of radiostrontium in calcareous soil. J Radioanal Nucl Chem 242:727-730 